\title{
New Androgen Receptor Axis-Targeted Agents in the Treatment of Nonmetastatic Castration-Resistant Prostate Cancer: From Bench to Clinical Trials
}

\author{
Jeong Hee Hong \\ Department of Urology, Dankook University College of Medicine, Cheonan, Korea
}

Bone metastasis is a common sign of disease progression in nonmetastatic castration-resistant prostate cancer (nmCRPC). It has been known to be associated with significant morbidity and mortality. Delaying or preventing development of distant metastasis is the ideal goal of treatment. There had been no standard treatment options available for patients with nmCRPC before 2018. Recent approval of new androgen receptor axis-targeted agents in the management of $\mathrm{nmCRPC}$ has led to rapid evolution and is worthy of detailed investigation. (Korean $\mathrm{J}$ Urol Oncol 2020;18:99-108)

Key Words: Castration-resistant prostate neoplasms • Neoplasm metastasis • Androgen receptor antagonists

\section{INTRODUCTION}

Nonmetastatic castration-resistant prostate cancer (nmCR $\mathrm{PC}$ ) is defined by a progressively rising prostate-specific antigen (PSA) level despite a castrate level of testosterone, without definite radiologic evidence of metastatic disease on conventional imaging modalities. ${ }^{1,2}$ These patients represent a heterogeneous population with regard to risk of progression to metastatic disease, which some cancers progress aggressively while others show an indolent course. ${ }^{3}$ Prior to 2018, there was no approved treatment recommendation for nmCRPC patients. Men with nmCRPC were basically managed with continuous androgen deprivation therapy to main-

Received December 3, 2019, Revised December 16, 2019

Accepted December 17, 2019

Corresponding Author: Jeong Hee Hong

Department of Urology, Dankook University Hospital, Dankook University College of Medicine, 201 Manghyang-ro, Dongnam-gu, Cheonan 31116, Korea

E-mail: hjh178@gmail.com

Tel: +82-41-550-3944, Fax: +82-41-553-6635

ORCID: https://orcid.org/0000-0003-2937-8552 tain castrate serum level of testosterone. The following attempts have been considered for patients with nmCRPC such as clinical trial or observation until the occurrence of metastasis or secondary hormone therapy. The secondary hormone therapy included an addition of first-generation antiandrogen, antiandrogen withdrawal or using other second-line hormonal agents such as estrogen or ketoconazole, none of which has shown any proven survival benefit. ${ }^{4}$ Over the past year, novel second-generation androgen receptor axis-targeted agents (ARTAs) have led to a new paradigm shift in managing patient with nmCRPC. The management of nmCRPC has, therefore, become a major challenge. This review will discuss the recent advances and future direction for the management of nmCRPC using new ARTAs.

\section{U.S. FOOD AND DRUG ADMINISTRATION APPROVAL OF NEW ARTAS}

\section{Abiraterone Acetate}

Abiraterone acetate (AA) is an irreversible, highly se-

This is an Open Access article distributed under the terms of the Creative Commons Attribution Non-Commercial License (http://creativecommons.org/licenses/by-nc/4.0/) which permits unrestricted non-commercial use, distribution, and reproduction in any medium, provided the original work is properly cited. 2020 (C) Copyright The Korean Urological Oncology Society and The Korean Prostate Society. All Rights Reserved. 
lective inhibitor of cytochrome P450 17A1 that deplete the production of adrenal and intratumoral androgens. ${ }^{5}$ AA was first described in 1993, and the efficacy of AA with prednisone was established in 3 randomized placebo-controlled trials. The U.S. Food and Drug Administration (FDA) initially approved AA with prednisone $10 \mathrm{mg}$ in April 2011 for patients with metastatic CRPC (mCRPC) who had received previously received docetaxel chemotherapy (COUAA-301 trial) and expanded the indication in December 2012 for men with chemotherapy-naive mCRPC (COU-AA302 trial). ${ }^{6,7}$ The COU-AA-301 and COU-AA-302 phase 3 trials showed an improvement in overall survival (OS) with AA by 3.9 months (14.8 months vs. 10.9 months) and 4.4 months (34.7 months vs. 30.3 months) compared to the placebo. In February 2018, the FDA has approved AA with prednisone $5 \mathrm{mg}$ for patients with high-risk, metastatic castration-sensitive prostate cancer (mCSPC) (LATTITUDE trial). ${ }^{8}$

\section{Enzalutamide}

Enzalutamide is a second-generation, nonsteroidal androgen receptor (AR) antagonist with greater affinity than the conventional first-generation AR antagonists, and patented in 2006. ${ }^{9}$ Enzalutamide competitively inhibits androgen binding to AR, AR nuclear translocation, and interaction with DNA. The FDA-approved enzalutamide for the treatment of mCRPC patients with previous docetaxel-based chemotherapy (AFFIRM trial) in August 2012 and men with chemotherapy-naive mCRPC (PREVAIL trial) in September 2014, respectively. ${ }^{10,11}$ The AFFIRM and PREV AIL phase 3 trials demonstrated a further gain in OS with enzalutamide by 3.8 months (18.4 months vs. 13.6 months) and 2.2 months (32.4 months vs. 30.2 months) compared to the placebo. In July 2018, the FDA has approved a new indication of enzalutamide for the treatment of men with nmCRPC (PROSPER trial). ${ }^{12}$

\section{Apalutamide}

Apalutamide is another second-generation, nonsteroidal antiandrogen that binds with high affinity to the ligandbinding domain of $\mathrm{AR}$ and inhibits $\mathrm{AR}$ translocation to the nucleus, DNA binding capacity, and AR-medicated transcription, which are similar to enzalutamide. ${ }^{13}$ The potential advantages of apalutamide compared to enzalutamide has shown on its preclinical development include a maximal antitumor effect at a lower dose, and greater efficacy at lower steady-state plasma- and brain-levels, possibly indicating a higher therapeutic index and lower risk of seizure. ${ }^{13}$ Apalutamide was initially described in 2007, and was the first medication to be approved specifically for the treatment of nmCRPC in February 2018 (SPARTAN trial). ${ }^{14}$ The FDA has recently approved apalutamide for the management of patients with mCSPC in September 2019 (TITAN trial). ${ }^{15}$

\section{Darolutamide}

Darolutamide is a novel, nonsteroidal AR antagonist with a unique molecular structure that is different from other second-generation AR antagonists. ${ }^{16}$ It also competitively inhibits androgen binding to AR, AR nuclear translocation, and AR-mediated transcription. In preclinical study, darolutamide and its metabolite bound to both wild-type and mutant AR, thus retain its full antagonist activity even in AR mutations which have known to cause resistance to first- and second-generation AR antagonists. ${ }^{16}$ It has shown negligible blood-brain barrier penetration and low binding affinity for $\gamma$-aminobutyric acid type A receptor, which suggests less central nervous system-related adverse events (AEs) such as fatigue, dizziness, cognitive impairment, and seizure. ${ }^{17}$ Darolutamide was described in 2011, and this drug was approved for the treatment of men with nmCRPC in July 2019 (ARAMIS trial). ${ }^{18}$

Drug approval with novel ARTAs has moved toward earlier stages of prostate cancer from the postchemotherapy mCRPC, chemotherapy-naive $\mathrm{mCRPC}$, to the high-risk nmCRPC and, in the case of AA, to high-risk mCSPC. A summary of the new ARTAs is presented (Table 1).

\section{EMERGING OF NEW ARTAS IN THE FIELD OF nmCRPC}

Patients with nmCRPC are at high risk of developing metastasis or death from prostate cancer, with one-third of patients progressing to metastatic disease, one-fifth dying, and up to $42 \%$ experiencing one of these 2 events within 2 years of diagnosis for nmCRPC. Baseline PSA and PSA rise kinetics are known to independent predictors for the risk of metastasis. ${ }^{19}$ But, until recently, there was no optimal 


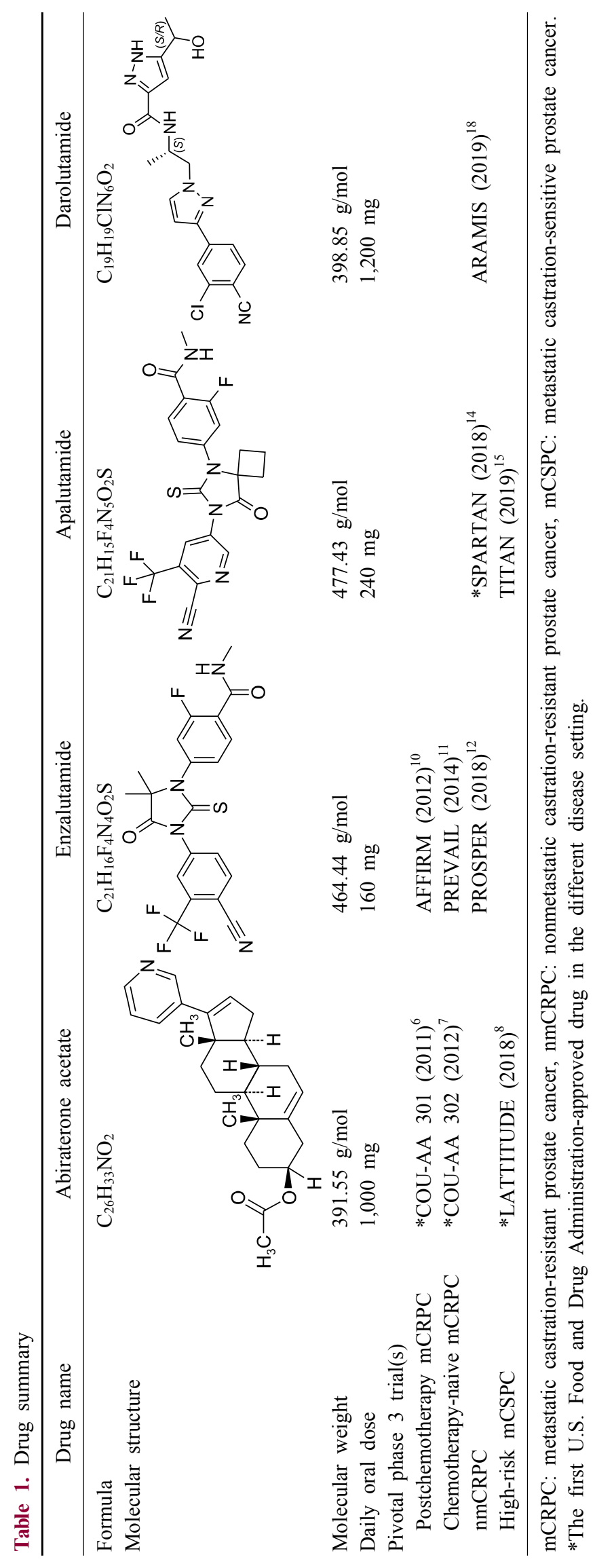


treatment for these patients. It has been demonstrated that new ARTAs improve OS in patients with chemotherapynaive $\mathrm{mCRPC}$ and in postchemotherapy mCRPC. ${ }^{20}$ Based on the success of new ARTAs in the treatment of mCRPC, several clinical trials were conducted for the treatment of high risk, nmCRPC patients. Before entering into the main body of the text, 2 questions should be kept in mind for the application of new ARTAs in the nmCRPC setting.

Do all asymptomatic, nmCRPC patients need to be treated? Men with nmCRPC consist of heterogeneous spectrum of the disease defined by a gradual rise in PSA and insensitive conventional imaging techniques. One of the strongest predictors of metastasis or death in men with nmCRPC is the PSA doubling time (PSADT). ${ }^{21,22}$ A phase 3 clinical trial examined the efficacy of denosumab in patients with nmCRPC at high-risk of metastases including baseline PSA $\geq$ $8 \mathrm{ng} / \mathrm{mL}$ or PSADT $\leq 10$ months. It has shown that shorter PSADT was associated with faster development of bone metastasis. A total of 1,432 men with nmCRPC were assigned to receive monthly subcutaneous denosumab $120 \mathrm{mg}$ or placebo. Denosumab increased median bone-metastasisfree survival for 4 months compared with placebo (29.5 months vs. 25.2 months; hazard ratio [HR], 0.85; $\mathrm{p}=0.028$ ), but it did not improve OS (43.9 months vs. 44.8 months; HR, 1.01; $\mathrm{p}=0.91$ ). There was an inflection point at a PSADT of around 8 months, where patient with shorter PSADT showed a dramatic increase in the risk of developing metastasis or death. ${ }^{21}$ An observational study of 441 men with nmCRPC also demonstrated that PSADT less than 9 months was closely associated with higher prostate cancer-specific mortality and all-cause mortality. The cutoff thresholds for risk stratification in men with nmCRPC have been proposed. $^{22}$ These results confirmed the evidence linking PSA kinetics to development of metastasis or death in men with nmCRPC.

What is an adequate surrogate to predict on the survival in managing patients with nmCRPC? The well-known limitation of clinical trials in prostate cancer is that it requires a long-term follow-up period to assess the impact of the new therapeutic intervention. Metastasis-free survival (MFS) is defined as the time from beginning of treatment to the first detection of distant metastasis or death of any cause. The advantage of using a surrogate such as MFS rather than OS is the ability to observe the number of required events earlier. Almost all of the patients who die from prostate cancer ultimately develop distant metastases to bone or other viscera prior to their death. The majority $(86 \%)$ of incidence flow into mCRPC states was from the nmCRPC clinical state. ${ }^{23}$ The Intermediate Clinical Endpoints in Cancer of the Prostate study, a meta-analysis of 28 randomized trials, showed that MFS is closely related with OS in clinically localized prostate cancer with an approximate $15 \%$ chance of dying prostate cancer over 10 years. ${ }^{24}$ In addition, radiographic progression-free survival (PFS) was a highly predictive factor for OS in the $\mathrm{mCPRC}$ setting according to the COU-AA-302 and PREVAIL results. ${ }^{25,26}$ Thus, MFS can allow an expeditious surrogate endpoint for survival that is increasingly recognized in clinical trials from the FDA standpoint for regulatory approval. ${ }^{27}$

\section{CLINICAL TRIALS OF NEW ARTAS IN THE FIELD OF nmCRPC}

\section{Phase 2 Clinical Trials}

\section{1) STRIVE trial (enzalutamide vs. bicalutamide)}

The STRIVE (Safety and Efficacy Study of Enzalutamide Versus Bicalutamide in Men with Prostate Cancer) trial enrolled the 396 patients with chemotherapy-naive CRPC either metastatic $(n=257,65 \%)$ or nonmetastatic $(n=139$, $35 \%){ }^{28}$ The patients were randomly assigned to receive enzalutamide $160 \mathrm{mg}$ or bicalutamide $50 \mathrm{mg}$ daily. The primary endpoint was PFS, defined as the time from initiation of treatment to a progression event including PSA progression or radiographic progression or death. The PFS was not yet reached with enzalutamide and 8.6 months with bicalutamide in men with nmCRPC (HR, 0.24; $\mathrm{p}<0.001)$. The secondary endpoints showed more beneficial in the enzalutamide group than in the bicalutamide group: time to PSA progression (not yet reached vs. 11.1 months; HR, 0.18; $\mathrm{p}<0.001$ ), PSA decline of $\geq 50 \%$ (91\% vs. $42 \%$, $<<0.001)$, and radiographic PFS (not yet reached vs. not yet reached; HR, 0.24; $\mathrm{p}<0.001)$. Notably, in men treated with enzalutamide, more favorable results with regard to PFS and PSA progression were observed in the nmCRPC disease state than in the mCRPC: PFS (not yet reached in nmCRPC vs. 16.5 months in mCRPC), PSA progression (not yet reached vs. 24.9 months), and PSA decline of $\geq 50 \%$ ( $91 \%$ vs. $76 \%$ ). This was the first study to suggest a potential benefit 
of new ARTAs in the nmCRPC setting.

\section{2) IMAAGEN trial (abiraterone acetate)}

The IMAAGEN (Impact of Abiraterone Acetate in Prostate-Specific Antigen) study recruited the high-risk, nmCRPC patients with baseline $\mathrm{PSA} \geq 10 \mathrm{ng} / \mathrm{mL}$ or $\mathrm{PSADT} \leq 10$ months. ${ }^{29}$ The 131 patients received once daily AA 1,000 $\mathrm{mg}$ plus prednisone $5 \mathrm{mg}$ in customary 28-day treatment cycles. The primary endpoint was the proportion of men obtaining a PSA reduction of $\geq 50 \%$ during cycles $1-6$. Of total patients, 44 men (34\%) remained on treatment, with a median follow-up of 40.0 months. One hundred 6 patients $(86.9 \%)$ achieved a $50 \%$ reduction or greater in PSA by the end of cycle 6 . The time to PSA progression and estimated radiographic PFS was 28.7 months and 41.4 months, respectively. However, this study has some limitations including no comparative arm, uncertain calculation of time to metastasis, and no available MFS data.

\section{Phase 3 Clinical Trials}

\section{1) SPARTAN trial (apalutamide vs. placebo)}

(1) Clinical efficacy

The SPARTAN (Selective Prostate Androgen Receptor Targeting with ARN-509) was a multicenter, double-blind, placebo-controlled, phase 3 trial of apalutamide in patients with high-risk nmCRPC who had rapidly rising PSA values with a PSADT $\leq 10$ months. ${ }^{14}$ This trial was conducted at 332 sites in 26 countries. Sixteen percent of patients had $\mathrm{N} 1$ disease, defined as pelvic lymph nodes $<2 \mathrm{~cm}$ of diameter in the short axis below the aortic bifurcation, at study entry. A total of 1,207 patients were randomized in a 2:1 fashion to receive either apalutamide $240 \mathrm{mg}$ /day $(\mathrm{n}=806)$ or placebo $(n=401)$. The primary endpoint was MFS. Secondary endpoints were time to metastasis, PFS which defined as the time to the first detection of local or distant metastasis on imaging or death, time to symptomatic progression, OS, and time to the first use of cytotoxic chemotherapy.

With a median follow-up of 20.3 months, apalutamide significantly improved MFS compared to placebo (40.5 months vs. 16.2 months; HR, 0.28; $<<0.001$ ), representing a 2-year delay in the development of distant metastasis. The favorable MFS of apalutamide was consistent across all subgroups. All secondary endpoints were in favor of apalu- tamide: time to metastasis (40.5 months vs. 16.6 months; HR, 0.27; $<<0.001$ ), PFS (40.5 months vs. 14.7 months; $\mathrm{HR}, 0.29 ; \mathrm{p}<0.001)$, and time to symptomatic progression (not yet reached vs. not yet reached; HR 0.45; $<<0.001$ ). The time to PSA progression was not yet reached in the apalutamide group as compared to 3.7 months in the placebo group. (HR, 0.06). The apalutamide group showed an $89.7 \%$ decrease in median PSA value while placebo group showed a $40.2 \%$ increase at 3 months after randomization. Treatment discontinuation due to disease progression was $19.3 \%$ in the apalutamide arm and $52.8 \%$ in the placebo arm. The percentage of men receiving subsequent treatment for $\mathrm{mCRPC}$ was $52.5 \%$ in the apalutamide group and $77.8 \%$ in the placebo group. AA plus prednisone was the most common subsequent therapeutic drug. At the time of the analysis, the median PFS2 (PFS on subsequent treatment from randomization) was not yet reached in the apalutamide arm and 39.0 months in the placebo arm (HR, 0.49; $\mathrm{p}<0.001$ ), with a $51 \%$ risk reduction of subsequent treatment.

\section{(2) Adverse events}

Grade 3 or 4 AEs occurred in $45.1 \%$ of patients with apalutamide arm and $34.2 \%$ with placebo arm. The percentage of patients with serious AEs was similar in both groups (24.8\% vs. 23.1\%). The following AEs were higher in the apalutamide group than in the placebo group: fatigue $(30.4 \%$ vs. $21.1 \%)$, rash $(23.8 \%$ vs. $5.5 \%)$, falls (15.6\% vs. $9.0 \%)$, fracture $(11.7 \%$ vs. $6.5 \%)$, hypothyroidism $(8.1 \%$ vs. $2.0 \%)$, and seizure $(0.2 \%$ vs. $0.0 \%)$. However, the majority of AEs were grade 2 or less. Treatment discontinuation due to AEs was more frequent in the enzalutamide group $(10.6 \%$ vs. $7.0 \%)$.

\section{2) PROSPER trial (enzalutamide vs. placebo) \\ (1) Clinical efficacy}

The PROSPER (Safety and Efficacy Study of Enzalutamide in Patients With Nonmetastatic Castration-Resistant Prostate Cancer) was a double-blind, placebo-controlled, phase 3 trial of enzalutamide and recruited patients with high-risk nmCRPC who are at high risk for progression based on a PSADT $\leq 10$ months. ${ }^{12}$ The trial was conducted more than 300 sites in 32 countries. A total of 1,401 patients were randomly assigned in a $2: 1$ ratio to receive either enzalutamide $160 \mathrm{mg}(\mathrm{n}=933)$ or placebo $(\mathrm{n}=468)$ once 
daily. The primary endpoint was MFS. Secondary endpoints included time to PSA progression, PSA response rate (PSA decrease of $\geq 50 \%$ from baseline), time to initiation of subsequent antineoplastic therapy, quality-of-life assessments, and OS.

Enzalutamide treatment significantly decreased the risk of distant metastasis or death compared to placebo (23\% vs. 49\%). The MFS was 36.6 months for men treated with enzalutamide and 14.7 months for men with placebo (HR, 0.29 ; $<<0.001$ ), demonstrating a $71 \%$ risk reduction of radiographic progression or death. The MFS benefit of enzalutamide was consistent across all the prespecified subgroups. Patients receiving enzalutamide had longer time to PSA progression than the placebo group (37.2 months vs. 3.9 months; HR, 0.07; $<<0.001)$, more PSA response rate $(76 \%$ vs. $2 \%$ ), and delayed time to first use of an antineoplastic therapy (39.6 months vs. 17.7 months; HR, 0.21; p<0.001). The proportion of patients experiencing radiographic progression or death in the enzalutamide arm was 50\% less than that of the placebo arm (23\% vs. $49 \%)$. Treatment discontinuation due to progressive disease was $14.8 \%$ in the enzalutamide group compared to $47.4 \%$ in the placebo group. The most common subsequent therapy was AA plus prednisone $(37.7 \%$ vs. $36.4 \%)$.

\section{(2) Adverse events}

The AEs of enzalutamide were consistent with those reported in previous phase 3 clinical trials for patients with mCRPC. ${ }^{10,11}$ Grade 3 or 4 AEs were reported in $31.4 \%$ of patients in the enzalutamide group and $23.4 \%$ in the placebo group. A higher percentage of patients receiving enzalutamide had severe AEs than did those receiving placebo $(24.3 \%$ vs. $18.3 \%)$. Fatigue was the most common AE in patients with enzalutamide (32.6\% vs. $13.8 \%$ ). Patients receiving enzalutamide had higher rate of falls or nonpathologic fractures compared to placebo group (17\% vs. $8 \%$ ). AEs of special interest occurred more frequently in the enzalutamide group than the placebo group including hypertension $(12.3 \%$ vs. $5.4 \%)$, major cardiovascular events $(5.2 \%$ vs. $2.8 \%$ ), mental impairment disorders (5.2\% vs. $1.9 \%)$, and convulsion $(0.3 \%$ vs. $0.0 \%)$. Discontinuation of the treatment due to AEs were more common in the enzalutamide group ( $9.3 \%$ vs. $6.0 \%)$.

\section{3) ARAMIS trial (darolutamide vs. placebo) (1) Clinical efficacy}

The ARAMIS (Androgen Receptor Antagonizing Agent for Metastasis-free Survival) was double-blind, placebo-controlled, phase 3 trial of darolutamide in men with nmCRPC and a PSADT $\leq 10$ months. ${ }^{18}$ The trial was conducted at 409 sites in 36 countries. Similar to the SPARTAN trial, patients with pelvic lymph nodes which located below the aortic bifurcation and measuring $<2 \mathrm{~cm}$ in the short axis were allowed (21.6\%). A total of 1,509 patients were randomized in a 2:1 ratio to receive either darolutamide 600 mg $(n=955)$ or placebo $(n=554)$ twice daily. Patients who have had previous seizure or conditions predisposing to seizure were not excluded from the study. The primary endpoint was MFS. Secondary endpoints included OS, time to pain progression, time to first symptomatic skeletal event, and time to first cytotoxic chemotherapy.

The median MFS with darolutamide was similar to those of 2 previous phase 3 randomized trials (SPARTAN, PROSPER) in patients with nmCRPC. The MFS was 40.4 months in the darolutamide group as compared to 18.4 months in the placebo group (HR, 0.41; $<<0.001$ ), translating to a $59 \%$ risk reduction of metastasis or death. The MFS of darolutamide was consistently favorable among all subgroups. Darolutamide showed greater benefits than placebo for all secondary endpoints: OS (not yet reached vs. not yet reached; HR, $0.71 ; \mathrm{p}=0.045)$, time to pain progression (40.3 months vs. 25.4 months; HR, 0.65; $\mathrm{p}<0.001$ ), time to cytotoxic chemotherapy (not yet reached vs. 38.2 months; HR, 0.43 ; $<<0.001$, and time to symptomatic skeletal event (not yet reached vs. not yet reached; HR, 0.43; $\mathrm{p}=0.01$ ). Other exploratory endpoints similarly favored darolutamide group including PFS (36.8 months vs. 14.8 months; HR, 0.38; $\mathrm{p}<0.001)$ and time to PSA progression (33.2 months vs. 7.3 months; HR, 0.13; p<0.001).

\section{(2) Adverse events}

Grade 3 or 4 AEs were observed in $24.7 \%$ of patients in the darolutamide arm and $19.5 \%$ in the placebo arm. The incidence of grade $5 \mathrm{AEs}$ in both groups was comparable (3.9\% vs. $3.2 \%)$. The incidence of AEs was generally similar in the darolutamide and placebo groups with the exception of fatigue $(12.1 \%$ vs. $8.7 \%)$, but which was less common than in the SPARTAN or PROSPER trial. In addition, AEs of interest reported much lower incidence than 
the previous 2 trials including hypertension (6.6\%), falls (4.2\%), dizziness (4.5\%), and cognitive disorder (0.4\%). Although patients with a history of seizure were allowed to recruit the trial, seizure occurred rarely and similar in either arm at $0.2 \%$. AEs led to discontinuation of assigned regimen were similar in both groups $(8.9 \%$ vs. $8.7 \%)$. A summary of pivotal nmCRPC phase 3 trials with new ARTAs is described (Table 2).

\section{PROMISING IMPACT OF NEW IMAGING TECHNIQUES}

The conventional imaging techniques for the evaluation of distant metastasis are computed tomography (CT) and bone scan, but they have limited accuracy. CT has a poor performance in detection of metastatic lymph nodes in a meta-analysis (pooled sensitivity $42 \%$ and specificity $82 \%) .{ }^{30}$ Similarly, other meta-analysis has shown that bone scan has a pooled sensitivity of $59 \%$ and specificity of $75 \%$ on a per-lesion basis for detection of bone metastasis. ${ }^{31}$

Positron emission tomography (PET) using ${ }^{18} \mathrm{~F}$-fluorodeoxyglucose, the workhorse radiotracer in PET, has not found preference in prostate cancer because it shows poor glucose activity. Often, there is significant overlap in the uptake between malignancy and benign disease of the prostate. Furthermore, high urinary excretion of radiotracer may obscure pathologic uptake. ${ }^{32}$ Hence, last 2 decades have seen the development of new radioisotracers. Fatty

Table 2. Summary of new ARTAs trials in nmCRPC

\begin{tabular}{|c|c|c|c|c|c|c|c|c|c|}
\hline \multirow[b]{2}{*}{ Variable } & \multicolumn{3}{|c|}{ SPARTAN $^{14}$} & \multicolumn{3}{|c|}{ PROSPER $^{12}$} & \multicolumn{3}{|c|}{ ARAMIS $^{18}$} \\
\hline & $\begin{array}{l}\text { Apaluta } \\
\text { mide } \\
(\mathrm{n}=806)\end{array}$ & $\begin{array}{l}\text { Placebo } \\
(n=401)\end{array}$ & HR & $\begin{array}{c}\text { Enzaluta } \\
\text { mide } \\
(n=933)\end{array}$ & $\begin{array}{l}\text { Placebo } \\
(n=468)\end{array}$ & HR & $\begin{array}{l}\text { Daroluta } \\
\text { mide } \\
(\mathrm{n}=955)\end{array}$ & $\begin{array}{l}\text { Placebo } \\
(n=554)\end{array}$ & HR \\
\hline \multirow{2}{*}{ Inclusion criteria } & \multicolumn{3}{|c|}{ cN0-1M0 CRPC } & \multicolumn{3}{|c|}{ cN0M0 CRPC } & \multicolumn{3}{|c|}{ cN0-1M0 CRPC } \\
\hline & PSAD & \multicolumn{2}{|c|}{$\leq 10$ months } & $\begin{array}{l}\text { PSAD } \\
\text { PSA }\end{array}$ & \multicolumn{2}{|c|}{$\begin{array}{l}\leq 10 \text { months } \\
\geq 2 \mathrm{ng} / \mathrm{mL}\end{array}$} & \multicolumn{3}{|c|}{$\begin{array}{c}\text { PSAD } \leq 10 \text { months } \\
\text { PSA } \geq 2 \mathrm{ng} / \mathrm{mL}\end{array}$} \\
\hline No. of patients & \multicolumn{3}{|c|}{1,207} & \multicolumn{3}{|c|}{1,401} & \multicolumn{3}{|c|}{1,509} \\
\hline Median duration of follow-up (mo) & \multicolumn{3}{|c|}{20.3} & \multicolumn{3}{|c|}{18.5} & \multicolumn{3}{|c|}{17.9} \\
\hline Median baseline PSA (ng/mL) & 7.7 & \multicolumn{2}{|l|}{7.9} & 11.1 & \multicolumn{2}{|l|}{10.2} & \multicolumn{3}{|c|}{9.7} \\
\hline Median baseline PSADT (mo) & 4.4 & \multicolumn{2}{|l|}{4.5} & 3.8 & \multicolumn{2}{|l|}{3.6} & 4.4 & \multicolumn{2}{|l|}{4.7} \\
\hline \multicolumn{10}{|l|}{ Stratification parameters } \\
\hline Baseline PSADT $\leq 6$ mo & $71.5 \%$ & \multicolumn{2}{|l|}{$70.8 \%$} & $76.6 \%$ & \multicolumn{2}{|l|}{$77.1 \%$} & $69.8 \%$ & \multicolumn{2}{|l|}{$67.0 \%$} \\
\hline Use of bone sparing agent (yes) & $10.2 \%$ & \multicolumn{2}{|l|}{$9.7 \%$} & $11.2 \%$ & \multicolumn{2}{|l|}{$10.3 \%$} & $3.2 \%$ & \multicolumn{2}{|l|}{$5.8 \%$} \\
\hline Presence of LNs on imaging (yes) & $16.5 \%$ & \multicolumn{2}{|l|}{$16.2 \%$} & N/A & $\mathrm{N} / \mathrm{A}$ & & $17.1 \%$ & $28.5 \%$ & \\
\hline Primary endpoint & & & & & & & & & \\
\hline MFS (mo) & 40.5 & 16.2 & 0.28 & 36.6 & 14.7 & 0.29 & 40.4 & 18.4 & 0.41 \\
\hline Secondary endpoints & & & & & & & & & \\
\hline OS (mo): interim analysis & NYR & 39.0 & 0.70 & NYR & NYR & 0.80 & NYR & NYR & 0.71 \\
\hline PFS (mo) & 40.5 & 14.7 & 0.29 & N/A & N/A & & 36.8 & 14.8 & 0.38 \\
\hline Time to PSA progression (mo) & NYR & 3.7 & 0.06 & 37.2 & 3.9 & 0.07 & 33.2 & 7.3 & 0.13 \\
\hline Confirmed PSA response $\geq 50 \%$ & $89.7 \%$ & $2.2 \%$ & & $76.3 \%$ & $2.3 \%$ & & N/A & $\mathrm{N} / \mathrm{A}$ & \\
\hline Discontinued study treatment & $39.1 \%$ & $70.1 \%$ & & $32.0 \%$ & $62.4 \%$ & & $35.5 \%$ & $63.9 \%$ & \\
\hline $\begin{array}{l}\text { Treatment discontinuation due to } \\
\text { progression }\end{array}$ & $19.3 \%$ & $52.8 \%$ & & $14.8 \%$ & $47.4 \%$ & & N/A & N/A & \\
\hline AEs & & & & & & & & & \\
\hline Any grade AEs & $96.5 \%$ & $93.2 \%$ & & $86.9 \%$ & $77.4 \%$ & & $83.2 \%$ & $76.9 \%$ & \\
\hline Grade 3 or 4 AEs & $45.1 \%$ & $34.2 \%$ & & $31.4 \%$ & $23.4 \%$ & & $24.7 \%$ & $19.5 \%$ & \\
\hline Treatment discontinuation due to AEs & $10.6 \%$ & $7.0 \%$ & & $9.3 \%$ & $6.0 \%$ & & $8.9 \%$ & $8.7 \%$ & \\
\hline All cause of death & $1.2 \%$ & $0.3 \%$ & & $3.4 \%$ & $0.9 \%$ & & $4.3 \%$ & $3.4 \%$ & \\
\hline
\end{tabular}

ARTAs: androgen receptor axis-targeted agents, nmCRPC: nonmetastatic castration-resistant prostate cancer, HR: hazard ratio, PSA: prostate-specific antigen, PSADT: PSA doubling time, LN: lymph node, MFS: metastasis-free survival, OS: overall survival, PFS: progression-free survival, AE: adverse event, NYR: not yet reached, N/A: not available. 
acid oxidation, rather than glycolysis, is the dominant metabolic pathway in prostate cancer. In addition, during cell membrane turnover, carbon and choline uptake are increased in prostate cancer. Therefore, acetate and choline radiolabeled with $\mathrm{C}$ or $\mathrm{F}$ have been favored in prostate cancer. ${ }^{33}$ The increase amino acid turnover in prostate cancer also promoted the use of ${ }^{18} \mathrm{~F}$-fluciclovine, a synthetic leucine analogue. ${ }^{34}$ Of late, much attention has been on developing radiotracer ligands targeted at the prostate-specific membrane antigen (PSMA), a cell surface protein whose expression is more specific to prostate than other tissue. PSMA expression shows a positive correlation with tumor aggressiveness, metastatic disease, and castrate resistance. The PSMA-ligand complex is readily internalized and released into the cytoplasm of prostate cancer cells, which makes PSMA an attractive target for diagnostic imaging. ${ }^{35}$ Novel tracers for PET scans such as ${ }^{11} \mathrm{C}$-choline, ${ }^{18} \mathrm{~F}$-fluciclovine, ${ }^{68} \mathrm{Ga}$-PSMA have shown improved sensitivity for detection of metastatic lesions in advanced prostate cancer. $^{36-39}$ Newer and more sensitive imaging techniques are expected to improve the detection rate of metastasis, which will lead to less patient population that meets the definition of nmCRPC.

\section{CONCLUSIONS}

The advent of new, second-generation ARTAs has dramatically changed the management landscape for men with mCRPC. Conversely, there has been no consensus recommendation for the treatment of nmCRPC. Three recent phase 3 trials (SPARTAN, PROSPER, and ARAMIS) using of new ARTAs have demonstrated clear MFS benefit compared to the placebo as the primary endpoint. Nearly $60 \%-$ $70 \%$ of risk reduction and 2 years delay in the development of metastases or death were reported. The secondary endpoints all met with the exception of OS that is not yet mature. Based on current available data, new ARTAs represent equivalent clinical efficacy for the treatment of patients with nmCRPC. The 2019 National Comprehensive Cancer Network guideline update included the category 1 option of apalutamide or darolutamide, or enzalutamide as a systemic therapy for nmCRPC patients with PSADT $\leq 10$ months. ${ }^{40}$ Although safety profiles showed that new ARTAs are generally well tolerated, AEs of interest such as fall, car- diovascular, and central nervous system-related toxicity were more frequently found compared to the placebo. These AEs have negatively impacted the health-related quality of life. Therefore, surveillance without intervention may be considered, particularly for PSADT $>10$ months and/or when the patient is frail with limited life expectancy. Novel imaging modalities may contribute to discriminate between nmCRPC and mCRPC. Further studies are necessary to better understand for the patients who will most likely to benefit from earlier treatment with new ARTAs in nmCRPC.

\section{CONFLICT OF INTEREST}

The authors claim no conflicts of interest.

\section{REFERENCES}

1. Mottet N, Bellmunt J, Bolla M, Briers E, Cumberbatch MG, De Santis M, et al. EAU-ESTRO-SIOG guidelines on prostate cancer. Part 1: screening, diagnosis, and local treatment with curative intent. Eur Urol 2017;71:618-29.

2. Scher HI, Morris MJ, Stadler WM, Higano C, Basch E, Fizazi K, et al. Trial design and objectives for castration-resistant prostate cancer: updated recommendations from the prostate cancer clinical trials working group 3 . J Clin Oncol 2016;34:1402-18.

3. Luo J, Beer TM, Graff JN. Treatment of nonmetastatic castration-resistant prostate cancer. Oncology (Williston Park) 2016;30:336-44.

4. Kucuk O, Fisher E, Moinpour CM, Coleman D, Hussain $\mathrm{MH}$, Sartor AO, et al. Phase II trial of bicalutamide in patients with advanced prostate cancer in whom conventional hormonal therapy failed: a Southwest Oncology Group study (SWOG 9235). Urology 2001;58:53-8.

5. O'Donnell A, Judson I, Dowsett M, Raynaud F, Dearnaley $\mathrm{D}$, Mason $\mathrm{M}$, et al. Hormonal impact of the 17alpha-hydroxylase/C(17,20)-lyase inhibitor abiraterone acetate (CB7630) in patients with prostate cancer. Br J Cancer 2004;90:2317-25.

6. de Bono JS, Logothetis CJ, Molina A, Fizazi K, North S, $\mathrm{Chu} \mathrm{L}$, et al. Abiraterone and increased survival in metastatic prostate cancer. N Engl J Med 2011;364:1995-2005.

7. Ryan CJ, Smith MR, de Bono JS, Molina A, Logothetis $\mathrm{CJ}$, de Souza P, et al. Abiraterone in metastatic prostate cancer without previous chemotherapy. $\mathrm{N}$ Engl J Med 2013;368:138-48.

8. Fizazi K, Tran N, Fein L, Matsubara N, RodriguezAntolin A, Alekseev BY, et al. Abiraterone plus prednisone in metastatic, castration-sensitive prostate cancer. 
N Engl J Med 2017;377:352-60.

9. Tran C, Ouk S, Clegg NJ, Chen Y, Watson PA, Arora V, et al. Development of a second-generation antiandrogen for treatment of advanced prostate cancer. Science 2009; 324:787-90.

10. Scher HI, Fizazi K, Saad F, Taplin ME, Sternberg CN, Miller $\mathrm{K}$, et al. Increased survival with enzalutamide in prostate cancer after chemotherapy. N Engl J Med 2012; 367:1187-97.

11. Beer TM, Armstrong AJ, Rathkopf DE, Loriot Y, Sternberg CN, Higano CS, et al. Enzalutamide in metastatic prostate cancer before chemotherapy. N Engl J Med 2014;371:424-33.

12. Hussain M, Fizazi K, Saad F, Rathenborg P, Shore N, Ferreira U, et al. Enzalutamide in men with nonmetastatic, castration-resistant prostate cancer. N Engl J Med 2018; 378:2465-74.

13. Clegg NJ, Wongvipat J, Joseph JD, Tran C, Ouk S, Dilhas A, et al. ARN-509: a novel antiandrogen for prostate cancer treatment. Cancer Res 2012;72:1494-503.

14. Hadaschik BA, Graff JN, Olmos D, Mainwaring PN, Lee $\mathrm{JY}$, Uemura $\mathrm{H}$, et al. Apalutamide treatment and metastasis-free survival in prostate cancer. N Engl J Med 2018; 378:1408-18.

15. Chi KN, Agarwal N, Bjartell A, Chung BH, Pereira de Santana Gomes AJ, Given R, et al. Apalutamide for metastatic, castration-sensitive prostate cancer. N Engl J Med 2019;381:13-24.

16. Moilanen AM, Riikonen R, Oksala R, Ravanti L, Aho E, Wohlfahrt G, et al. Discovery of ODM-201, a new-generation androgen receptor inhibitor targeting resistance mechanisms to androgen signaling-directed prostate cancer therapies. Sci Rep 2015;5:12007.

17. izazi K, Albiges L, Loriot Y, Massard C. ODM-201: a new-generation androgen receptor inhibitor in castrationresistant prostate cancer. Expert Rev Anticancer Ther 2015;15:1007-17.

18. Fizazi K, Shore N, Tammela TL, Ulys A, Vjaters E, Polyakov $\mathrm{S}$, et al. Darolutamide in nonmetastatic, castration-resistant prostate cancer. N Engl J Med 2019;380:1235-46.

19. Smith MR, Kabbinavar F, Saad F, Hussain A, Gittelman MC, Bilhartz DL, et al. Natural history of rising serum prostate-specific antigen in men with castrate nonmetastatic prostate cancer. J Clin Oncol 2005;23:2918-25.

20. Cornford P, Bellmunt J, Bolla M, Briers E, De Santis M, Gross T, et al. EAU-ESTRO-SIOG guidelines on prostate cancer. Part II: treatment of relapsing, metastatic, and castration-resistant prostate cancer. Eur Urol 2017;71:630-42.

21. Smith MR, Saad F, Oudard S, Shore N, Fizazi K, Sieber $\mathrm{P}$, et al. Denosumab and bone metastasis-free survival in men with nonmetastatic castration-resistant prostate cancer: exploratory analyses by baseline prostate-specific anti- gen doubling time. J Clin Oncol 2013;31:3800-6.

22. Howard LE, Moreira DM, De Hoedt A, Aronson WJ, Kane CJ, Amling CL, et al. Thresholds for PSA doubling time in men with non-metastatic castration-resistant prostate cancer. BJU Int 2017;120:E80-6.

23. Scher HI, Solo K, Valant J, Todd MB, Mehra M. Prevalence of prostate cancer clinical states and mortality in the united states: estimates using a dynamic progression model. PLoS One 2015;10:e139440.

24. Xie W, Regan MM, Buyse M, Halabi S, Kantoff PW, Sartor O, et al. Metastasis-free survival is a strong surrogate of overall survival in localized prostate cancer. J Clin Oncol 2017;35:3097-104.

25. Morris MJ, Molina A, Small EJ, de Bono JS, Logothetis CJ, Fizazi K, et al. Radiographic progression-free survival as a response biomarker in metastatic castration-resistant prostate cancer: COU-AA-302 results. J Clin Oncol 2015; 33:1356-63.

26. Rathkopf DE, Beer TM, Loriot Y, Higano CS, Armstrong $\mathrm{AJ}$, Sternberg $\mathrm{CN}$, et al. Radiographic progression-free survival as a clinically meaningful end point in metastatic castration-resistant prostate cancer: the PREVAIL randomized clinical trial. JAMA Oncol 2018;4:694-701.

27. Beaver JA, Kluetz PG, Pazdur R. Metastasis-free survival a new end point in prostate cancer trials. N Engl J Med 2018;378:2458-60.

28. Penson DF, Armstrong AJ, Concepcion R, Agarwal N, Olsson C, Karsh L, et al. Enzalutamide versus bicalutamide in castration-resistant prostate cancer: the STRIVE trial. J Clin Oncol 2016;34:2098-106.

29. Ryan CJ, Crawford ED, Shore ND, Underwood W 3rd, Taplin ME, Londhe A, et al. The IMAAGEN study: effect of abiraterone acetate and prednisone on prostate specific antigen and radiographic disease progression in patients with nonmetastatic castration resistant prostate cancer. J Urol 2018;200:344-52.

30. Hövels AM, Heesakkers RA, Adang EM, Jager GJ, Strum $\mathrm{S}$, Hoogeveen YL, et al. The diagnostic accuracy of CT and MRI in the staging of pelvic lymph nodes in patients with prostate cancer: a meta-analysis. Clin Radiol 2008;63: 387-95.

31. Shen G, Deng $\mathrm{H}, \mathrm{Hu} \mathrm{S}$, Jia Z. Comparison of choline-PET/CT, MRI, SPECT, and bone scintigraphy in the diagnosis of bone metastases in patients with prostate cancer: a meta-analysis. Skeletal Radiol 2014;43:1503-13.

32. Salminen E, Hogg A, Binns D, Frydenberg M, Hicks R. Investigations with FDG-PET scanning in prostate cancer show limited value for clinical practice. Acta Oncol 2002; 41:425-9.

33. Liu Y. Fatty acid oxidation is a dominant bioenergetic pathway in prostate cancer. Prostate Cancer Prostatic Dis 2006;9:230-4. 
34. Oka S, Okudaira H, Yoshida Y, Schuster DM, Goodman MM, Shirakami Y. Transport mechanisms of trans-1-amino-3-fluoro[1-(14)C]cyclobutanecarboxylic acid in prostate cancer cells. Nucl Med Biol 2012;39:109-19.

35. Mease RC, Foss CA, Pomper MG. PET imaging in prostate cancer: focus on prostate-specific membrane antigen. Curr Top Med Chem 2013;13:951-62.

36. Fanti S, Minozzi S, Castellucci P, Balduzzi S, Herrmann $\mathrm{K}$, Krause BJ, et al. PET/CT with (11)C-choline for evaluation of prostate cancer patients with biochemical recurrence: meta-analysis and critical review of available data. Eur J Nucl Med Mol Imaging 2016;43:55-69.

37. Bach-Gansmo T, Nanni C, Nieh PT, Zanoni L, Bogsrud TV, Sletten H, et al. Multisite experience of the safety, detection rate and diagnostic performance of fluciclovine (18F) positron emission tomography/computerized tomography imaging in the staging of biochemically recurrent prostate cancer. J Urol 2017;197:676-83.
38. Perera M, Papa N, Christidis D, Wetherell D, Hofman MS, Murphy DG, et al. Sensitivity, specificity, and predictors of positive 68ga-prostate-specific membrane antigen positron emission tomography in advanced prostate cancer: a systematic review and meta-analysis. Eur Urol 2016;70: 926-37.

39. Fendler WP, Weber M, Iravani A, Hofman MS, Calais J, Czernin J, et al. Prostate-specific membrane antigen ligand positron emission tomography in men with nonmetastatic castration-resistant prostate cancer. Clin Cancer Res 2019; 25:7448-54.

40. National Comprehensive Cancer Network. NCCN guidelines for patients: prostate cancer (v4. 2019) [Internet]. Fort Wathington (PA): National Comprehensive Cancer Network; 2019 [cited 2019 Aug 19]. Available from: https:/www.nccn.org/patients/guidelines/content/PDF/ prostate-patient.pdf. 